\section{Percepção dos pescadores artesanais sobre os impactos da COVID-19 na atividade pesqueira do Reservatório Billings, São Paulo, Brasil}

\author{
Artisanal fishermen perception on the impacts of \\ COVID-19 on fishing activity at Billings \\ reservoir, São Paulo, Brazil
}

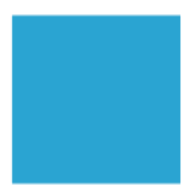

Revista Extensão em Foco
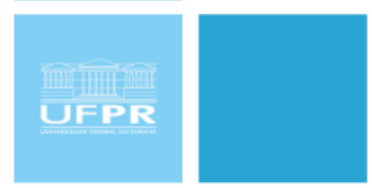

ISSN $2358-7180$

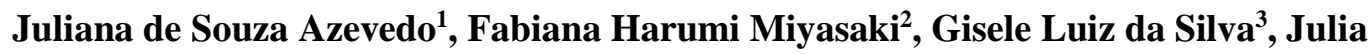 \\ Giacomet $^{4}$, Tais Frazão do Amaral ${ }^{5}$
}

\begin{abstract}
RESUMO
O Reservatório Billings é considerado um dos maiores e mais importantes mananciais voltado ao abastecimento de água da região metropolitana de São Paulo (RMSP). A pesca artesanal se caracteriza como a principal fonte de renda de muitos usuários da Billings. Em virtude da crise sanitária ocasionada pela pandemia de COVID-19, populações humanas que residem em áreas vulneráveis ou que desempenham atividades profissionais autônomas como a pesca, têm sido impactada negativamente pelas estratégias de isolamento e distanciamento social. Deste modo, esta pesquisa objetivou obter dados sobre a percepção dos pescadores artesanais, que dependem da pesca no sistema Billings como fonte de renda, sobre a pesca durante o período inicial da pandemia de COVID-19. Os dados foram obtidos através de um questionário semiestruturado e aplicado aos pescadores usuários do reservatório Billings. Dos respondentes, $83 \%$ estão ativos na atividade pesqueira, havendo uma maior proporção de pescadoras $(58 \%)$ do que de pescadores $(42 \%)$. $92 \%$ acreditam que a pandemia de COVID-19 influenciou de alguma forma a venda do pescado na Semana Santa de 2020 e $100 \%$ observou a diminuição na quantidade de pescado comparado com 2019. Além disso, 33\% dos respondentes afirmam não ter conseguido vender sua produção. Alguns(as) pescadores(as) acreditam que a comercialização do pescado seria melhorada se os pescadores tivessem condições próprias de estocar e vender a própria produção. A partir destes resultados, espera-se poder traçar estratégias para lidar com a COVID-19 e o isolamento decorrente dela, junto as autoridades locais.
\end{abstract}

Palavras-chave: Coronavírus. Pandemia. Pesca. Reservatórios. Meio Ambiente

\title{
ABSTRACT
}

Billings reservoir is one of the largest and important compartments to water provision of the Metropolitan Region of São Paulo (MRSP). The artisanal fishing is the main activity of source of income for many

\footnotetext{
${ }^{1}$ Doutora em Oceanografia Química. Universidade Federal de São Paulo (Unifesp), Diadema, São Paulo, Brasil. E-mail: juliana.azevedo@unifesp.br. Orcid: http://orcid.org/0000-0002-8231-9669

${ }^{2}$ Graduanda em Ciências Ambientais. Universidade Federal de São Paulo (Unifesp), Diadema, São Paulo, Brasil. E-mail: fabimiyasaki@gmail.com. Orcid: https://orcid.org/0000-0002-5240-0968

${ }^{3}$ Bacharel em Ciências Ambientais. Universidade Federal de São Paulo (Unifesp), Diadema, São Paulo, Brasil. E-mail: gisele_luiz_silva@ hotmail.com. Orcid: https://orcid.org/0000-0001-9323-6941

${ }^{4}$ Graduanda em Ciências Biológicas. Universidade Federal de São Paulo (Unifesp), Diadema, São Paulo, Brasil. E-mail: giacomett.julia@unifesp.br. Orcid: https://orcid.org/0000-0002-8460-7701

${ }^{5}$ Bacharel em Ciências Ambientais. Universidade Federal de São Paulo (Unifesp), Diadema, São Paulo, Brasil. E-mail: taiisfrazao@gmail.com. Orcid: https://orcid.org/0000-0003-0568-3763
} 
Billings users. For consequence of the health crisis bring on by the COVID-19 outbreak, human populations that live in vulnerable areas or that perform autonomous professional activities such as artisanal fishing, have been negatively impacted by strategies of isolation and social distance. Thus, the goal of this research was to obtain data about the perception of the artisanal fishermen, which depend on fishing from Billings system as a source of income, about the fishing situation concerning the initial outbreak of COVID-19. The data were obtained by semi-structured questionnaire that was applied to fishermen users of Billings reservoir. $83 \%$ of the interviewee are active in fishing, with a major proportion of women (58\%) than men (42\%) in the fishing. $92 \%$ believe that the COVID-19 outbreak has influenced in some way in fish's sale during the Holy Week 2020 and 100\% noted the decrease in the number of fish compared to 2019. Furthermore, $33 \%$ of the fishermen say they were unable to sell their production. Some fishermen believe that the commercialization of the fish would be improved if they were able to store and sell their own production. From these results, it is expected to thinks and to do strategies in order to deal with COVID-19 and the isolation resulting from it, together with local authorities.

Keywords: Coronavirus. Pandemic. Fishing. Reservoirs. Environment

\section{INTRODUÇÃO}

Os reservatórios são sistemas aquáticos continentais contidos em bacias de drenagem, caracterizados por serem permanentes ou transitórios (BARBOSA et al., 2019). No Brasil os reservatórios são extremamente importantes para garantir o abastecimento de água à população, geração de energia elétrica através de hidrelétricas e também acabam por ser utilizadas para meios de lazer e pesca, apresentando assim relevância ambiental, econômica, paisagística e social (POMPÊO; CARLOS, 2004; ANA, 2010).

No Estado de São Paulo, a represa Billings se configura como um dos maiores e mais importantes reservatórios de água para a região metropolitana da cidade de São Paulo (RMSP). O sistema Billings está inserido no território da Bacia Hidrográfica do Alto Tietê, ocupa uma área de $582,8 \mathrm{~km}^{2}$ e está subdividido em oito braços principais: Alvarenga, Bororé, Capivari, Cocaia, Pedra Branca, Rio Grande, Rio Pequeno e Taquacetuba. Quanto aos limites urbanos, os municípios de Diadema, Ribeirão Pires, Santo André, São Bernardo do Campo e São Paulo, representam parte da extensão da represa, que possui cerca de $127 \mathrm{Km}^{2}$ de espelho d'água, com uma vazão natural média estimada em $12,3 \mathrm{~m}^{3} / \mathrm{s}$. Os principais rios e córregos que a formam são o Rio Grande e o Rio Jurubatuba (SIGRH, 2019).

A partir de 1948, com a finalidade de propiciar a atividade pesqueira na região, iniciou-se a introdução de peixes na represa Billings, sendo os primeiros grupos a serem inseridos as carpas (Cyprinus carpio) e tilápias (Tilapia rendalli e Tilapia melanopleura) 
(ROCHA; PEREIRA; PÁDUA, 1985). Segundo Alves da Silva et al. (2009) além da pesca comercial que ocorre no reservatório Billings, uma grande parte da população que reside em seu entorno sobrevive com a pesca familiar. Muitas destas pessoas que se sustentam por meio da pesca, mesmo em baixa escala, conseguem vender os pescados em feiras locais e para o próprio consumo, o que auxilia na economia local. É importante salientar que a pesca exercida de modo artesanal pode indicar padrões de qualidade ambiental, que levam em conta a conservação de recursos pesqueiros em áreas de maior quantidade de pescado (EMBRAPA, 2012).

A ocupação irregular próxima a corpos hídricos leva a uma série de problemáticas, tanto para a população, como a erosão e assoreamento do solo, quanto para a fauna existente na área, como a contaminação dos principais rios por dejetos domésticos (PONTES et al., 2012). Segundo Rocha, Pereira e Pádua (1985) as problemáticas da ocupação humana no entorno da Represa Billings retratam um dos principais fatores da diminuição da diversidade da ictiofauna e da saúde dos peixes encontrados na represa.

Segundo Maruyama et al. (2018), é muito importante garantir o nível de produção pesqueira economicamente rentável e a integridade dos ecossistemas, considerando que a pesca responsável significa também buscar, em longo prazo, benefícios econômicos, ecológicos e sociais. Silva (2014) ressalta que a pesca artesanal apresenta papel fundamental na manutenção da biodiversidade, pois mantém o equilíbrio e manutenção dos ecossistemas e das comunidades ribeirinhas.

Em virtude da crise sanitária ocasionada pela pandemia de COVID-19, populações humanas que residem em áreas vulneráveis, como ao entorno da represa Billings, ou que desempenham atividades profissionais autônomas, tem sido impactada pelas estratégias de isolamento e distanciamento social (KNIGHT et al., 2020).

O novo coronavírus SARS-CoV-2 (Síndrome Respiratória Aguda Grave causada pelo coronavírus tipo 2) é um betacoronavirus, identificado como o agente etiológico causador da COVID-19. Os CoVs ganharam destaque público após o surto da Síndrome Respiratória Aguda Grave (SARS-CoV) em 2003, na China. Em 2016, também na China, outro coronavírus causou um surto fatal em porcos, onde mais de 24.000 leitões morreram, causando grandes perdas econômicas para o país (CHEN et al., 2020; SEAH et al., 2020). O surto provocado pelo SARS-CoV-2 (WHO, 2020), se iniciou em dezembro de 2019, na cidade de Wuhan, província de Hubei (China), e logo se espalhou para outros países. 
O SARS-CoV-2 possui cerca de 79\% de similaridade com o vírus SARS-CoV que causou o surto da Síndrome Respiratória (SARS) em 2002-2003 (WHO, 2020; SOHRABIA et al., 2020; LU et al., 2020). Sendo assim, o conhecimento sobre a COVID19 deriva de estudos sobre coronavírus semelhantes que são transmitidos por vias respiratórias entre humanos. O reservatório inicial do vírus ainda é desconhecido, porém estudos estão sendo realizados, a fim de obter maiores respostas a respeito da contaminação pelo vírus e os possíveis hospedeiros (WHO, 2020).

Os Coronavírus (CoVs) são vírus de RNA envelopados, conhecidos por afetarem uma ampla gama de aves e mamíferos, desde os animais silvestres, domésticos e ferais como morcegos, camelos, gatos e cachorros, até animais de maior porte e importância econômica para a produção, como suínos (CHEN et al., 2020; QIU, 2020). Raramente o coronavírus que infecta os animais não humanos são transmitidos aos humanos (spillover) (Ministério da Saúde - https://coronavirus.saude.gov.br/sobre-a-doenca\#o-que-e-covid). Seu nome é derivado da palavra corona, que em latim significa coroa, devido a presença de projeções em sua superfície que confere a eles uma aparência semelhante a uma coroa (SEAH et al., 2020).

A subfamília $\mathrm{CoV}$ está se expandindo rapidamente, e hoje, consiste em quatro gêneros conhecidos $(\gamma, \beta, \mathrm{a}$ e $\delta$-CoV) e trinta e oito espécies únicas, sendo sete delas prejudiciais aos humanos (FAN et al., 2019; SEAH et al., 2020). Os $\alpha$-CoV e $\beta$-CoV são comuns por infectarem mamíferos, enquanto que os $\gamma-\mathrm{CoV}$ e $\delta$-CoV são conhecidos por infectarem aves (FAN et al., 2019). Entretanto, ainda existem espécies desconhecidas a serem identificadas.

Os CoVs são os maiores vírus de RNA conhecidos, e sua alta capacidade de obter mutações facilitam sua transmissão, fazendo com que se tornem um patógeno preocupante (SEAH et al., 2020). Os surgimentos esporádicos e os surtos de novos tipos de coronavírus os tornam uma grande ameaça à saúde global, sendo muito provável a ocorrência de novos surtos no futuro devido às mudanças climáticas e ao aumento das interações de humanos com animais. Atualmente, ainda não existe uma terapia antiviral específica ou vacina eficaz para o SAR-CoV-2, onde os principais tratamentos são de suporte. As melhores medidas a serem adotadas se relacionam ao diagnóstico precoce, notificação, isolamento social, uso de máscaras e evitar aglomerações para prevenir a infecção por coronavírus (CHEN et al., 2020). 
Assim, e partir do exposto acima, esta pesquisa tem por objetivo apresentar dados sobre a percepção dos pescadores de pequena escala, que dependem da pesca artesanal na represa Billings (SP, Brasil), como fonte de renda, assim como os potenciais efeitos que a pandemia de COVID-19 está tendo sobre a atividade pesqueira destes atores. Esta pesquisa também se propõe a obter conhecimentos que possam ser revertidos, no futuro, em ações que auxilie os pescadores artesanais que utilizam a represa Billings, no enfrentamento de crises como a ocasionada pela pandemia de COVID-19.

\section{MÉTODOS}

Este estudo foi realizado com os trabalhadores da pesca artesanal no Reservatório Billings, como parte do Projeto de extensão universitária "Peixe na Rede" (Proec-Unifesp $n^{\circ}$ 17.308).

O mapa com a indicação do sistema Billings (SP, Brasil) e dos núcleos de pesca foi construindo utilizando informações contidas em sites governamentais, artigos científicos e banco de dados de projetos de pesquisa da Unifesp, com utilização do sistema projetado de coordenadas Datum: Sirgas 2000/UTM zone 23S. Assim, informações sobre as massas d'água, limites de municípios e estados e áreas urbanas foram obtidas junto ao IBGE (2015) (ftp://geoftp.ibge.gov.br/cartas_e_mapas/bases_cartograficas_continuas/bc250/versao 2015/Shapefile/ , https://www.ibge.gov.br/geociencias/cartas-e-mapas/redesgeograficas/15789-areas-urbanizadas.html?=\&t=downloads), dados sobre a bacia hidrográfica da Billings pelo sistema DATAGEO, (2003) (http://datageo.ambiente.sp.gov.br/geoportal/catalog/search/resource/details.page?uui $\mathrm{d}=\%$ 7B5C97D050-75FD-4152-A5E3-2F24B1DCF0DF\%7D) e informações sobre os núcleos de pesca foram obtidas a partir de informações constantes em Alves da Silva (2009).

Para avaliar a percepção dos pescadores sobre o impacto da COVID-19 na atividade de pesca realizada no reservatório Billings, foi aplicado um questionário semiestruturado, composto por 13 perguntas de múltipla escolha e 1 pergunta discursiva sobre os possíveis impactos da pandemia de COVID-19 na atividade de pesca na Billings. Após submissão e aprovação pelo Comitê de Ética em Pesquisa da Instituição 
(CEP-Unifesp) (CEP/UNIFESP n ${ }^{\text {o. }}$ 0705/2020; CAAE n ${ }^{\text {o: }}$ 33949120.5.0000.5505) e em virtude do isolamento social imposto pela pandemia de COVID-19, os questionários foram disponibilizados no formato eletrônico, via plataforma Google Forms.

O questionário eletrônico foi construído contendo um preâmbulo de apresentação geral do projeto, seguido do Termo de Consentimento Livre e Esclarecido (TCLE) e posteriores perguntas. Após convites e aceites, de acordo com os procedimentos éticos, o Termo de Consentimento Livre e Esclarecido (TCLE) foi apresentado com as informações sobre a pesquisa para as devidas explicações e concordância. Pelo questionário, foram obtidos dados relacionados aos efeitos da pandemia de COVID-19 na atividade pesqueira dos pescadores, tais como interrupção da pesca durante o período de distanciamento social, produção e preço do pescado, além de modificações na composição e número de espécies pescadas durante o período da pandemia e recebimento de auxílio emergencial. Os pescadores foram contatados a partir de contato com as lideranças da pesca na Represa Billings, cadastradas na colônia de pescadores Z-17 “Orlando Feliciano" e destes aos demais pescadores usuários da Billings, seguindo assim, um modelo eletrônico, modificado da metodologia "bola de neve"6 (BAILEY, 1982). Os dados referentes às questões fechadas foram analisados de forma quantitativa, por meio de estatística descritiva simples.

\section{RESULTADOS E DISCUSSÃO}

A represa Billings foi originalmente criada para geração de energia elétrica e posteriormente, constatou-se sua utilidade no controle de enchentes e afastamento de efluentes industriais e domésticos da cidade de São Paulo, despejados no rio Tietê (PREFEITURA MUNICIPAL DE SANTO ANDRÉ, 2014). Seu uso é regido pela Lei Estadual no 13.579, de 13 de julho de 2009, que declara a Área de Proteção e Recuperação de Mananciais da Bacia Hidrográfica do Reservatório Billings - APRM-B, situada na Unidade de Gerenciamento dos Recursos Hídricos do Alto Tietê, como manancial de interesse regional para o abastecimento das populações atuais e futuras em consonância com a Lei Estadual n 9.866, de 28 de novembro de 1997, que dispõe sobre diretrizes e normas para a proteção e recuperação das bacias hidrográficas dos mananciais de interesse regional do Estado de São Paulo (GOVERNO DO ESTADO DE SÃO PAULO,

\footnotetext{
${ }^{6}$ Amostragem não probabilística utilizada por pesquisadores para acessar comunidades ou populações de baixa incidência e indivíduos de difícil acesso. Por esta metodologia, um potencial respondente indica outro, de sua rede de amigos e/ou conhecidos, fornecendo dados para sua localização (BAILEY, 1982).
} 
2010). Há cerca de 1 milhão de pessoas residindo no entorno da Billings, que abastece diretamente cerca de 2 milhões de pessoas residentes no município de Rio Grande da Serra e parcialmente nos municípios de Diadema, Ribeirão Pires, Santo André, São Bernardo do Campo e São Paulo (ALVES DA SILVA et al., 2010).

De acordo com Lei Federal no 11.959/2009 (BRASIL, 2009), a pesca artesanal é caracterizada pelo meio de produção próprio, com a utilização de embarcações de pequeno porte até 20 toneladas (BRASIL, 2009). Entretanto, segundo Oliveira e Silva (2012), a pesca artesanal vai muito além dessa categorização estabelecida pela legislação brasileira, devendo a classificação se relacionar de forma mais íntima com os diferentes petrechos de pesca utilizados, ao invés de analisar somente o porte da embarcação. Assim, a Lei $n^{\circ} 11.959 / 2009$ trata somente os instrumentos de pesca como uma observação secundária, porém, são eles quem definem a pesca artesanal.

Campos e Chaves (2016), consideram ainda que a pesca artesanal também inclui os pescadores de subsistência, já que eles apresentam apenas duas categorias, sendo elas a pesca industrial e a artesanal. A pesca artesanal correspondeu à 90\% dos pescadores brasileiros, em 2013 (CAMPOS; CHAVES, 2016), e segundo Coe (2016), esse número também é visto mundialmente, corroborando a sua suma importância tanto no setor econômico, como também socioambiental e cultural. De acordo com Campos e Chaves (2016), entre esses pescadores artesanais, a maioria se enquadra na classe dos profissionais, que além de pescar para a subsistência da família, conseguem colocar produtos excedentes para comercialização no mercado.

Rocha, Pereira e Pádua (1985) relatam que desde a década de 60, a atividade de pesca na represa era bastante intensa, através das colônias e núcleos de pesca localizados nas regiões do Riacho Grande e São Bernardo do Campo. A partir dos dados obtidos por Alves da Silva et al. (2009) e Azevedo et al. (2019), e com base na pesquisa qualiquantitativa realizada com os pescadores do sistema Billings (SP, Brasil), foi possível identificar 10 núcleos de pesca, que se mantém desde 2009 (Figura 1), demostrando assim a importância da pesca de pequena escala desempenhada na represa Billings como uma importante fonte de renda local.

Figura 1 - Mapa da área de estudo, com representação do sistema Billings (SP, Brasil) e indicação dos núcleos de pesca relatados por Alves da Silva et al. (2009). 


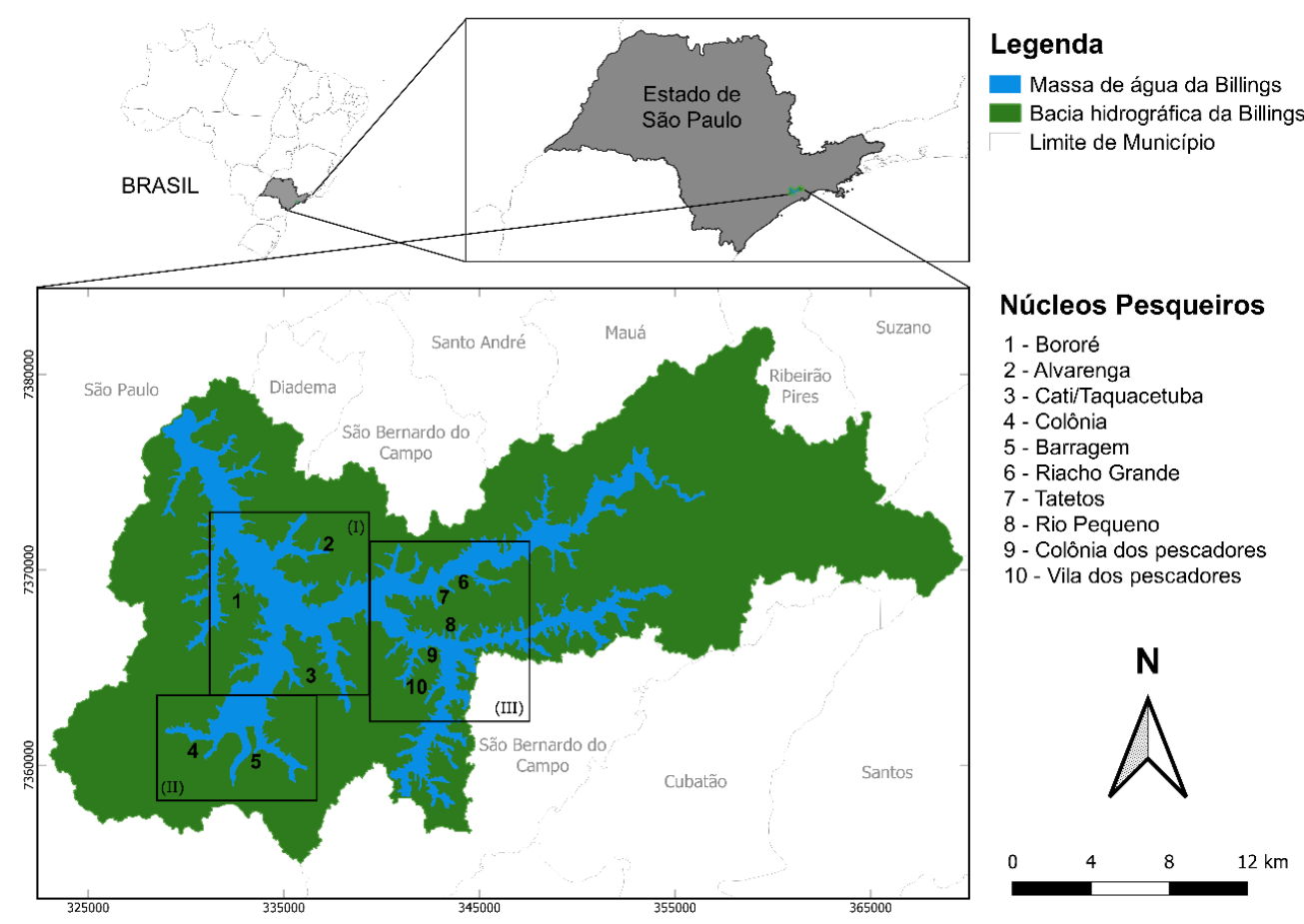

Fonte: Autoria própria (2021)

Embora os conhecimentos sejam importantes, traçar o perfil-socioeconômico dos pescadores artesanais também são fundamentais para os planos de manejo de estoque, visto que, não há como analisar o instrumento de captura, sem analisar quem são os pescadores que o utiliza (ALVES DA SILVA et al., 2009). Ainda faltam muitos dados em relação a quantidade e quais são os pescados retirados da natureza, o que influencia na tomada de decisões de políticas públicas e realocação de recursos para esse setor (OLIVEIRA et al., 2013).

A partir dos dados obtidos junto aos pescadores usuários da Billings (SP), foi possível caracterizar os respondentes quanto às suas características populacionais. $83 \%$ dos respondentes estão ativos como trabalhadores da pesca na represa Billings (SP), com maior proporção de pescadoras (58\%) em relação a atividade pesqueira realizada pelos homens (42\%). Quanto ao município de residência, 58\% dos pescadores residem em São Paulo, 34\% em São Bernardo do Campo e uma menor parcela reside no município de Diadema (8\%). Entretanto, $83 \%$ dos pescadores desenvolvem a atividade da pesca no mesmo município de residência. A atividade de pesca é realizada em grande parte por pescadores e pescadoras com faixa etária entre 45-55 anos (42\%) e maiores que 75 anos (25\%), revelando assim uma estreita relação temporal com a represa.

A maioria dos respondentes apresentam a pesca como função principal (91\%) e cerca de $41 \%$ dos respondentes se caracterizam como vendedores dos pescados. Dentre 
os petrechos de pesca mais utilizados, destaca-se a rede de emalhe $(91 \%)$, seguidos da rede de cerco e espinheis, em menor proporção dos respondentes (8\%).

A pandemia de COVID-19 trouxe uma desaceleração global na pesca comercial, seja de pequena quanto de grande escala (CLAVELLE, 2020; KEMP et al., 2020), criando condições para uma maior resiliência e recuperação ambiental de ambientes aquáticos já fortemente impactos. Kemp et al. (2020) consideram que em diversos países, como o Reino Unido, um dos mais afetados pela pandemia de COVID-19, que tiveram uma redução de até $50 \%$ na atividade pesqueira, esta queda esteve associada a fatores como a baixa demanda, queda de preços, fechamento de mercados de frutos do mar, preocupações com a saúde e segurança da tripulação.

A partir dos dados obtidos junto aos pescadores usuários do sistema Billings (SP, Brasil), em geral, a quantidade de peixes pescados neste ano (2020) está menor do que dos anos anteriores (Figura 2). Porém, o número de pescadores e o volume de água na represa diminuíram em relação ao ano passado (2019). 92\% dos respondentes acreditam que a pandemia de COVID-19 influenciou de alguma forma a venda do pescado na Semana Santa deste ano (2020), onde o principal impacto da pandemia de COVID-19 na pesca esteve relacionado com a maior dificuldade de venda da produção (50\%).

Figura 2 - Percepção dos pescadores artesanais sobre a produção do pescado e seus influenciadores.

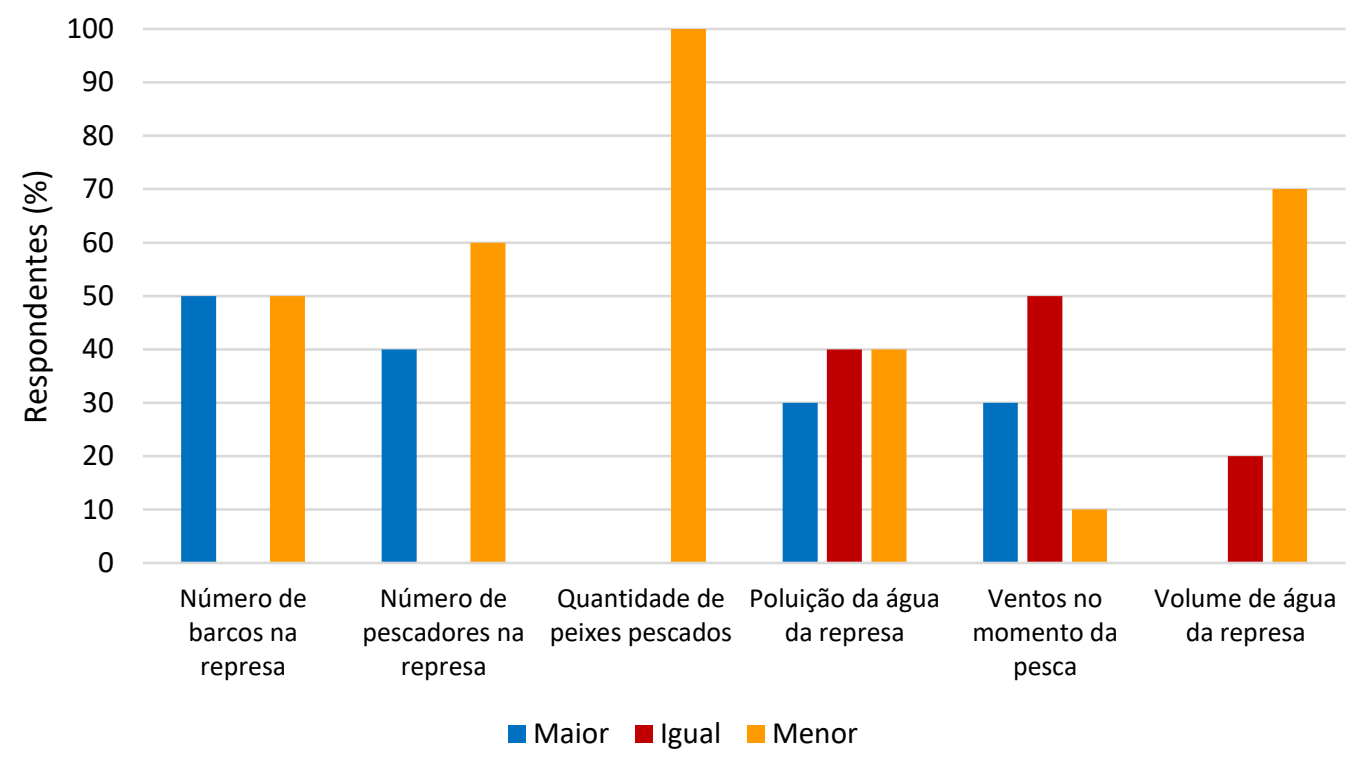

Fonte: Autoria própria (2021) 
Além disso, os trabalhadores da pesca da represa Billings, consideram que não conseguiram vender toda a produção (33\%), não tendo mercado para a venda destes produtos (33\%) (Figura 3). Em geral, a pandemia de COVID-19 dificultou a venda do pescado, reduziu a procura por peixes e deixou o atravessador mais caro, o que impossibilitou a venda total da produção. Tal fato, provavelmente também se relaciona ao aspecto cultural atribuído da população acreditar que o pescado oriundo da represa Billings possui baixa qualidade, em virtude principalmente da poluição de alguns setores antropizados na Billings.

Figura 3 - Percepção dos pescadores artesanais sobre a venda do pescado.

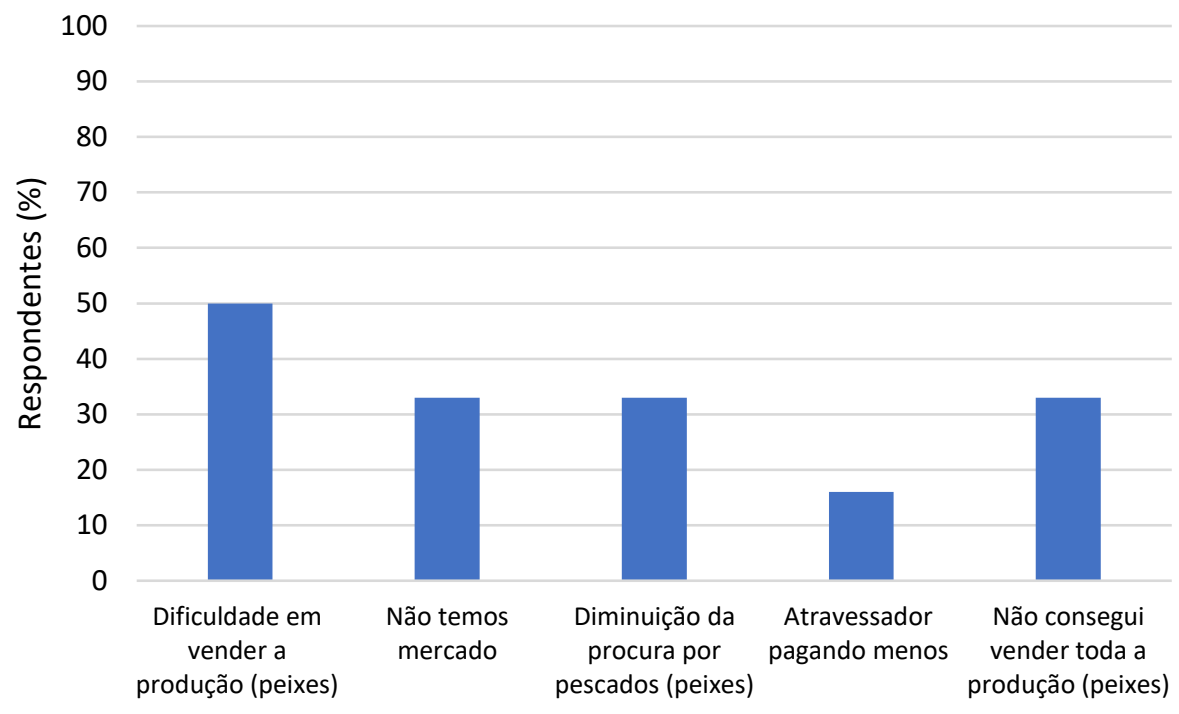

Fonte: Autoria própria (2021)

Apesar dos impactos negativos ocasionados pela pandemia, cerca de $41 \%$ dos respondentes recebem o auxílio financeiro do Bolsa Família e 33\% recebem o auxílio emergencial. Contudo, cerca de $8 \%$ dos respondentes não conseguiram o auxílio ou já recebem outros benefícios, como o Seguro Defeso. Estes resultados representam somente uma pequena parcela dos pescadores que conseguiram os auxílios financeiros, sendo que em muitos casos, ainda foi preciso exercer a pesca durante a pandemia, a fim de garantir o próprio sustento. Por fim, os pescadores acreditam que a comercialização do pescado seria melhorada se os pescadores tivessem condições próprias de estocar e vender o pescado. 
Embora a pandemia de COVID-19 tenha trazido um cenário precário no que concerne à saúde humana, em diversas áreas ao redor do mundo, verificou-se uma melhoria ambiental relacionada a redução do fluxo antrópico e das práticas de isolamento e distanciamento social. O estudo de Bar (2020), que traz um aglomerado de informações sobre os efeitos do distanciamento social pela COVID-19, destaca que cidades populosas da Europa e da Ásia como Madrid, Roma, Milão, Paris, Mumbai e Delhi, tiveram um declínio entre 40 e $54 \%$ na sua concentração de $\mathrm{NO}_{2}$ na atmosfera quando comparado com o ano anterior. Em Veneza (Itália) verificou-se a maior transparência das águas de seus canais devido a restrição do trafego de barcos motorizados. Já no Estado de São Paulo, Rosse et al. (2020) concluíram que as medidas de isolamento foram suficientes para alterar a dinâmica das concentrações dos poluentes atmosféricos.

Em um trabalho compilado por Bennett et al. (2020) sobre os efeitos sociais e econômicos associados aos pescadores de pequena escala, impostos pela pandemia de COVID-19, os autores relatam como principais efeitos negativos o fechamento de pescarias, aumento do risco a saúde dos pescadores, processadores do pescado e a comunidade local, aumento da pesca ilegal, aumento da vulnerabilidade e marginalização social. Por lado, como aspectos positivos os autores apresentam a partilha de alimentos, entregas coletivas, aumento de vendas locais e redução da pressão de pesca em alguns lugares.

A partir dos relatos de alguns pescadores/pescadoras do sistema Billings, conforme apresentado na íntegra abaixo, é perceptível a preocupação social, econômica e ambiental.

Considerações, ipsis litteris, dos respondentes (pescadores):

"Eu queria que a população tomasse mais consciência e não jogase lixos na represa né esgotos para não contaminar a nossa água que bebemos $e$ tiramos os frutos dela mais consciência"

"Estou pescando mas muito pouco porque não da pra ficar saindo p vender" 


\begin{abstract}
"Assim como tenho evitado comprar algum tipo de alimentos devido o manuseio, o povo também está arredio com a higiene"
\end{abstract}

A médio e longo prazo, a dificuldade no escoamento da pesca, em virtude das condições necessárias para venda do pescado, associado com um aumento na falta de interesse da população em comprar o pescado oriundo do sistema Billings, e intensificados durante a pandemia de COVID-19, pode-se marginalizar ainda mais um grupo populacional já marginalizado como os pescadores artesanais.

Assim, faz-se necessário uma ação com maior velocidade dos gestores e tomadores de decisão para implementação de políticas públicas voltadas a recuperação, garantia e melhoria dos serviços ecossistêmicos que reservatórios com histórico de impactação antrópica e fins de pesca possuem, como o sistema Billings.

Kinight et al. (2020) consideram que embora ineficazes para garantia de um mercado pesqueiro globalizado, a gestão e ações locais podem ser eficazes na manutenção da pesca local, reconhecendo as vulnerabilidades e necessidades de curto, médio e longo prazo dos pescadores artesanais. Neste contexto, é prioritário que os pescadores do sistema Billings ganhem uma visibilidade para que as demandas sociais, econômicas e ambientais possam ser minimizadas e não aumentadas neste e no pós período pandemia de COVID-19.

A pandemia de COVID-19 tem causado perdas na qualidade de vida, por decréscimo da atividade pesqueira dos pescadores artesanais na Billings. Relatos de pescadores da Billings, sugerem a existência de cerca de 400 famílias atuantes e dependentes da atividade da pesca na Billings.

Em virtude das práticas de isolamento e distanciamento social impostas pela pandemia da COVID-19, não foi possível realizar as entrevistas presencialmente com os pescadores. Assim, o uso de plataformas online ainda é uma dificuldade para grande parte destes atores, uma vez que muitos ainda possuem dificuldades tecnológicas, seja quanto ao acesso e/ou ao uso de plataformas online, para coleta de dados. Entretanto, em virtude das características populacionais, vulnerabilidade e outros aspectos socioambientais explicitados anteriormente, este número de respondentes da pesca possui sua importância e merece visibilidade. Em sua maioria, quando abordados presencialmente, os pescadores se mostram receptivos, acolhedores e desejosos de desenvolver práticas mais sustentáveis 
quanto a pesca e seu produto, atuando ainda de forma ativa na melhoria da qualidade dos serviços ecossistêmicos ofertados pela represa Billings, tais como os serviços de provisão relacionados a melhoria da qualidade da água do reservatório e a pesca, serviços culturais com fins paisagísticos e de turismo ecológico e dos serviços de suporte como a manutenção das áreas de várzeas da represa, oferta de peixes e outros.

Finalmente, espera-se que os resultados apresentados por este estudo possam subsidiar ações de políticas públicas voltadas a melhoria da qualidade socioambiental da população de pescadores artesanais que têm a pesca na Billings como principal fonte de renda e que vêm sofrendo efeitos negativos nesta atividade por decorrência da pandemia de COVID-19.

\section{AGRADECIMENTOS}

Os autores agradecem aos pescadores da Billings (SP) e a Pró-Reitoria de Extensão Universitária da Unifesp pelas bolsas Pibex concedidas.

\section{REFERENCIAS}

ANA - Agência Nacional de Águas. Barragens e Reservatórios, 2010. Disponível em:

$<$ https://www.ana.gov.br/gestao-da-agua/saiba-quemregula/reservatorios\#: :text=A\%20Ag\%C3\%AAncia\%20Nacional $\% 20 \mathrm{de} \% 20 \% \mathrm{C} 3 \% 81$ guas, volume \%20de\%20\%C3\%A1gua\%20que\%20sai).>. Acesso em: 20 outubro 2020.

ALVES DA SILVA, M. E. et al. Levantamento da pesca e perfil socioeconômico dos pescadores artesanais profissionais no reservatório Billings. Boletim do Instituto de Pesca, v. 35, n. 4, p. 531-543, 2009. Disponível em: https://www.pesca.sp.gov.br/35_4_531-543.pdf

BARBOSA, C. C. F.; NOVO, E. M. L. M.; MARTINS, V. S. Introdução ao Sensoriamento Remoto de Sistemas Aquáticos: princípios e aplicações. São José dos Campos: Instituto Nacional de Pesquisas Espaciais. 1. ed., 2019.

BAILEY, K. D. Methods of Social Research. New York: The Free Press, 4. ed., 1982.

BENNETT, N. J. et al. The COVID-19 Pandemic, Small-Scale Fisheries and Coastal Fishing Communities. Coastal Management, v. 48, n. 4, p. 336-347, 2020. doi: 10.1080/08920753.2020.1766937. 
BAR, H. COVID-19 lockdown: animal life, ecosystem and atmospheric environment. Environment, Development and Sustainability, 2020. doi: 10.1007/s10668-020-01002-7

BRASIL. Lei no 11.959, de 29 de Junho de 2009. Dispõe sobre a Política Nacional de Desenvolvimento Sustentável da Aquicultura e da Pesca, regula as atividades pesqueiras, revoga a Lei $\mathrm{n}^{\circ} 7.679$, de 23 de novembro de 1988, e dispositivos do DecretoLei $\mathrm{n}^{\circ}$ 221, de 28 de fevereiro de 1967, e dá outras providências. Brasília: DOU de 29/06/2009.

CAMPOS, A. G.; CHAVES, J. V. Perfil laboral dos pescadores artesanais no Brasil: insumos para o programa seguro defeso. Revista Mercado de Trabalho: conjuntura e análise, v. 60, n. 1, p. 63-73, 2016. Disponível em: http://repositorio.ipea.gov.br/bitstream/11058/6625/1/bmt60_perfil.pdf

CLAVELlE, T. Global Fisheries during COVID-19. Global Fishing Watch, 2020. Disponível em: https ://globalfishingwatch.org/data-blog/global-fisheries-duringcovid-19/. Acesso em: 08 nov. 2020.

CHEN, Y.; LIU, Q.; GUO, D.; Emerging coronaviruses: Genome structure, replication, and pathogenesis. Journal of Medical Virology, v. 92, p. 418-423, 2020. https://doi.org/10.1002/jmv.25681

COE, C. M. Avaliação da atividade pesqueira na comunidade de pescadores artesanais de Bitupitá, município de Barroquinha, Ceará. Ceará: Universidade Federal do Ceará, 2016 (Dissertação de Mestrado).

DATAGEO - Infraestrutura de dados espaciais ambientais do Estado de São Paulo. Limite da Bacia Billings. 2003. Disponível em: <http://datageo.ambiente.sp.gov.br/geoportal/catalog/search/resource/details.page?uuid $=\% 7 B 5 C 97 D 050-75 F D-4152-A 5 E 3-2 F 24 B 1 D C F 0 D F \% 7 D>$. Acesso em: 05 novembro 2020.

EMBRAPA - Empresa Brasileira de Pesquisa Agropecuária. Pesca: uma atividade estratégica para a conservação do Pantanal, 2012. Disponível em: < https://www.cpap.embrapa.br/pesca/online/PESCA2012_CPAP1.pdf >. Acesso em: 15 outubro 2020.

FAN, Y. et al. Bat Coronaviruses in China. Viruses, v. 11, p. 210, 2019. https://doi.org/10.3390/v11030210

GOVERnO DO ESTADO DE SÃO PAULO. Elaboração do Plano de Desenvolvimento e Proteção Ambiental da Bacia Hidrográfica do Reservatório 
Billings. Disponível em: http://pdpa.cobrape.com.br/Arquivos/Pdpas/PDPABillings.pdf. Acesso em: 10 julho 2019

KNIGHT, C. J. et al. COVID-19 reveals vulnerability of small-scale fisheries to global market systems. Lancet Planet Health, v. 4, n. 6, e219, 2020. doi: 10.1016/S2542-5196(20)30128-5

IBGE - Instituto Brasileiro de Geografia e Estatística. Brasil: Redes Geográficas. Áreas Urbanizadas. 2015.2 Disponível em: $<$ https://www.ibge.gov.br/geociencias/cartas-e-mapas/redes-geograficas/15789-areasurbanizadas.html?=\&t=downloads $>$. Acesso em: 5 novembro 2020.

IBGE - Instituto Brasileiro de Geografia e Estatística. Bases Cartográficas Continuas. 2015.2 Disponível em: <ftp://geoftp.ibge.gov.br/cartas_e_mapas/bases_cartograficas_continuas/bc250/versao2 015/Shapefile/>. Acesso em: 5 novembro 2020.

MARUYAMA, L. S.; CASTRO, P. M. G. de; PAIVA, P. de. Pesca artesanal no Médio e Baixo Tietê, São Paulo, Brasil: aspectos estruturais e socioeconômicos. Boletim do Instituto de Pesca, v. 35, n. 1, p. 61-81, 2018. Disponível em: <https://www.pesca.sp.gov.br/boletim/index.php/bip/article/view/838>. Acesso em: 20 janeiro 2020.

MINISTÉRIO DA SAÚDE - Governo Federal do Brasil. Sobre a doença. Disponível em: <https://coronavirus.saude.gov.br/sobre-a-doenca\#o-que-e-covid>. Acesso em: 5 novembro 2020

OLIVEIRA, O. M. B. A.; SILVA, V. L. O processo de industrialização do setor pesqueiro e a desestruturação da pesca artesanal no Brasil a partir do Código de Pesca de 1967. Sequência, v. 65, p. 329-357, 2012. http://dx.doi.org/10.5007/21777055.2012v33n65p329

OLIVEIRA, J. C. S. et al. Caracterização da pesca no Reservatório e áreas adjacentes da UHE Coaracy Nunes, Ferreira Gomes, Amapá - Brasil. Biota Amazônica, v. 3, n. 3, p. 83-96, 2013. doi: 10.18561/2179-5746/biotaamazonia.v3n3p83-96

POMPÊO, M. L. M; CARLOS, V. M. Portal de Ecologia Aquática - A represa Billings, um reservatório tropical urbano eutrofizado e as macrófitas aquáticas: aspectos ecológicos e diagnóstico ambiental. 2004. Disponível em: $<$ http://ecologia.ib.usp.br/portal/index.php?option=com_content\&view=article $\&$ id $=68 \&$ Itemid=461> Acesso em: 20 outubro 2020. 
PONTES, P. P.; MARQUES, A. R.; MARQUES, G. F. Efeito do uso e ocupação do solo na qualidade da água na micro-bacia do Córrego Banguelo - Contagem. Revista Ambiente e Água, v. 7, n. 3, p. 183-194, 2012. doi: 10.4136/1980-993X

PREFEITURA MUNICIPAL DE SANTO ANDRÉ. A represa Billings e o município de Santo André. 2014. Disponível em: $<$ https://www2.santoandre.sp.gov.br/index.php/2014-06-26-19-25-15/o-reservatoriobillings>. Acesso em: 20 outubro 2020.

SCIENTIFIC AMERICAN. How China's 'Bat Woman' Hunted Down Viruses from SARS to the New Coronavirus. Disponível em: https://www.scientificamerican.com/article/how-chinas-bat-woman-hunted-downviruses-from-sars-to-the-new-coronavirus1/ Acesso em: 20 novembro 2020.

ROCHA, A. A.; PEREIRA, D. N.; PÁDUA, H. B. Produtos de Pesca e Contaminantes Químicos na Água da Represa Billings, São Paulo (Brasil). Revista de Saúde Pública, v. 19, p. 401-10, 1985. Disponível em: https://www.scielo.br/scielo.php?pid=S0034$89101985000500003 \&$ script=sci_arttext\&tlng=pt

ROSSE, V. P. et al. São Paulo's atmospheric pollution reduction and its social isolation effect, Brazil. Air Quality, Atmosphere \& Health, 2020. doi: 10.1007/s11869020-00959-8

LU, R. et al. Genomic characterisation and epidemiology of 2019 novel coronavirus: implications for virus origins and receptor binding. The Lancet, v. 395, p. 565-574, 2020. doi: 10.1016/S0140-6736(20)30251-8

SEAH, I.; AGRAWAL, R. Can the Coronavirus Disease 2019 (COVID-19) Affect the Eyes? A Review of Coronaviruses and Ocular Implications in Humans and Animals. Ocular Immunology and Inflammation, v. 28, n. 3, p. 391-395, 2020. doi: $\underline{10.1080 / 09273948.2020 .1738501}$

SILVA, A. P. Boletim de Pesquisa e Desenvolvimento. Pesca artesanal brasileira. Aspectos conceituais, históricos, institucionais e prospectivos. Palmas: Embrapa Pesca e Aquicultura. 1. ed. 2014. ISSN 2358-6273.

SIGRH- Sistema Integrado de Gerenciamento de Recursos Hídricos do Estado de São Paulo. Apresentação. Disponível em: <http://www.sigrh.sp.gov.br/cbhat/apresentacao>. Acesso: 17 julho 2019. 
SOHRABIA, C. et al. World Health Organization declares global emergency: A review of the 2019 novel coronavirus (COVID-19). International Journal of Surgery, v. 76, p. 71-76, 2020.

WHO - World Health Organization. Director-General's Remarks at the Media Briefing on 2019-nCoV on 11 February 2020. Disponível em: $<$ https://www.who.int/dg/speeches/detail/who-director-general-s-remarks-at-the-mediabriefing-on-2019-ncov-on-11-february-2020>. Acesso em: 25 setembro 2020.

Recebido em: 14 de Março de 2021. Aceito em: 06 de Abril de 2021. 